\title{
A Study on Stroke in Young and Elderly in Rajiv Gandhi Government General Hospital, Chennai
}

\author{
P. Chitrambalam ${ }^{1}$, Dipti Baskar ${ }^{2}$, S. Revathy ${ }^{2}$ \\ ${ }^{1}$ Institute of Internal Medicine, Rajiv Gandhi Government General Hospital (RGGGH), Chennai, India; ${ }^{2}$ Madras Medical College, \\ Chennai, India. \\ Email: iim.rgggh@gmail.com
}

Received March 12 ${ }^{\text {th }}, 2012$; revised April 20 ${ }^{\text {th }}, 2012$; accepted May 10 ${ }^{\text {th }}, 2012$

\begin{abstract}
Stroke is a devastating and disabling cerebrovascular disease with some amount of residual deficit leading onto economic loss. Recent Indian studies have shown a stroke prevalence rate of $471.58 / 100,000$ population. This study was undertaken to analyse the clinical profile and to arrive at important factors contributing to stroke in $<45$ years group and $\geq 45$ years group. This is a descriptive, retrospective cross - sectional study carried out on acute CVA patients, admitted to the I.I.M., RGGGH, Chennai. 150 patients were studied over a period of 3 months in the $2011.20 \%$ of $<45$ years (young stroke) and $80 \%>/=45$ years constituted our study population. $18.4 \%$ and $22.2 \%$ of males and females respectively were young stroke patients. Only $33.3 \%$ of patients were brought to the hospital within 6 hours. $90 \%$ patients had mild GCS score $(>/=13 / 15)$ and presented with hemiplegia $76 \%$ and $18 \%$ had infarct and intracerebral hemorrhage $(\mathrm{ICH})$ respectively. Risk factors: Type A personality (70.7\%), Tobacco (60.7\%) and Alcohol (44.7\%) abuse, Systemic Hypertension (60.7\%), Diabetes Mellitus (33.3\%), Cardiac disorders (14\%). Stroke was seen to be more common in $\geq 45$ years but still young stroke carries paramount importance due to loss of productive years in these patients. Female predominance was seen in young stroke, with particular reference to puerperal period. Among the comorbid illness systemic hypertension followed by cardiac disorders had important contributing role in young strokes. Most of the patients with infarct and ICH were tobacco and alcohol abusers respectively. A holistic approach encompassing further research in factors involved in young stroke, public awareness, behavioural modification and comorbid medical illness management is the need for the hour.
\end{abstract}

Keywords: Cardiac Disease; Cerebral Infarction; Intracerebral Hemorrhage; Recurrent Pregnancy Loss; Recurrent Stroke; Stroke; Young Stroke

\section{Introduction}

Stroke is a devastating and disabling cerebrovascular disease with significant amount of residual deficit leading on to economic loss. It has been defined as a rapidly developing signs of focal (or global) disturbance of cerebral function with symptoms lasting for $\geq 24$ hours, or leading to death with no apparent cause other than vascular origin [1]. It is a collection of clinical syndromes resulting from cerebral ischemia to intracranial hemorrhage. In the west, it is the $3^{\text {rd }}$ most common cause of morbidity and mortality [2]. Though India was ranked among countries lacking sufficient stroke research data [3], some of the recent studies have elucidated the stroke pattern to considerable extent in our country with a prevalence rate of $471.58 / 100,000$ population [4]. Despite many studies prevail regarding stroke, still this major illness remain widely prevalent. Hence this study was undertaken to delineate the various aspects of stroke in our setup which shall be of immense use to the physicians who are required to manage the patients disabled by stroke. This study was conducted on acute cerebrovascular accidents (CVA) patients admitted to the Institute of Internal Medicine, Rajiv Gandhi Government General Hospital, Chennai, to assess and analyse the epidemiological, clinical and risk factor profile of these stroke victims with particular reference to $<45$ years (young stroke) and $\geq 45$ years age groups.

\section{Material \& Methods}

This is a descriptive, retrospective, cross sectional study carried out on Acute CVA Patients admitted to the Institute of Internal Medicine, Rajiv Gandhi Government General Hospital, Chennai. Patients admitted for hemiparesis other than CVA were excluded from the study. Sample size was 150 CVA patients. This study was conducted over a period of 3 months during the year 2011. Patient 
data collection forms were used to collect data on age, sex, educational status, occupation, Glascow Coma Scale (GCS) score, time of occurrence, time lapse, clinical profile and risk factors - Chronic Medical Illness-Systemic Hypertension (HT): Diagnosed and/or under treatment, Diabetes Mellitus (DM): Diagnosed and/or under treatment, Cardiac disorders (Ischemic heart disease, valvular heart disease, atrial fibrillation, cardiomyopathy, congenital heart diseases): Diagnosed and/or under treatment.

Adverse Personal Habits-Tobacco Abuse (Smoking, Chewing, Snuff), Alcohol abuse.

Personality Types-Type A: Ambitious, Aggressive, highly competitive; Type B: Apathetic, Patient, relaxed. Type A may be associated with cardiovascular diseases.

Statistical analysis was done by Pearson chi square test using SPSS 17.0 version software.

\section{Results}

Our study population consisted of $150 \mathrm{CVA}$ patients of which $20 \%(\mathrm{n}=30)$ were $<45$ years (young stroke) and $80 \%(\mathrm{n}=120)$ were $\geq 45$ years. Under the young stroke category $53.3 \%(n=16)$ were males and $46.7(\mathrm{n}=14)$ were females. $\geq 45$ years group consisted $59.2 \%(n=71)$ of males and $40.8 \%(n=49)$ of females. Among the males and females, young stroke constituted $18.4 \%(\mathrm{n}=16)$ and $22.2 \%(\mathrm{n}=14)$ respectively. $52 \%(\mathrm{n}=78)$ of our study population were illiterates and $48 \%(\mathrm{n}=72)$ were literates. $50 \%(\mathrm{n}=15)$ of $<45$ years and $52.5 \%(\mathrm{n}=64)$ of $\geq 45$ years were illiterates. Of the $41.3 \%(n=62)$ unemployed. $33.3 \%(\mathrm{n}=10)$ and $43.3 \%(\mathrm{n}=52)$, among males and females were unemployed respectively. With respect to the golden period of 6 hours, $33.3 \%(n=50)$ were brought to the medical attention within this period. $33.3 \%(n=10)$ of $<45$ years and $33.3 \%(n=40)$ of $\geq 45$ years were brought within this "Golden Period" (Table 1).

Table 1. Clinical profile in $<45$ years and $\geq 45$ years.

\begin{tabular}{lcc}
\hline${ }^{1}$ Clinical Profile & $\begin{array}{c}<45 \text { yrs } \\
(\mathrm{n}=30)\end{array}$ & $\begin{array}{c}\geq 45 \mathrm{yrs} \\
(\mathrm{n}=120)\end{array}$ \\
\hline${ }^{2}$ GCS Mild $(90 \% \mathrm{n}=135)$ & $83.3 \%$ & $91.7 \%$ \\
$\quad$ Left $(48 \% \mathrm{n}=72)$ & $46.7 \%$ & $48.3 \%$ \\
${ }^{3}$ Side of Plegia $\quad$ Right $(45.3 \% \mathrm{n}=68)$ & $50 \%$ & $44.2 \%$ \\
${ }^{4}$ Type of Plegia: Hemiplegia $(90 \%, \mathrm{n}=135)$ & $93.3 \%$ & $89.2 \%$ \\
${ }^{5}$ Speech Involvement: & $43.3 \%$ & $30.8 \%$ \\
Aphasia/Dysarthria $(33.3 \%, \mathrm{n}=50)$ & $63.3 \%$ & $67.5 \%$ \\
\hline Cranial Nerve Involvement $(60.7 \%, \mathrm{n}=91)$ & & \\
\hline
\end{tabular}

${ }^{1}$ Findings under the clinical profile given in this table are those which were encountered maximum. Other clinical findings seen are as follows; ${ }^{2} \mathrm{GCS}-$ Glascow coma scale Mild ( $\geq 13 / 15)$, Moderate ( 8 - 12/15), Severe $(<8 / 15)$; ${ }^{3}$ Side of Plegia - Left, Right, Both, cannot be assessed; ${ }^{4}$ Type of plegiaHemiplegia, Monoplegia, Cruciate, cannot be assessed; ${ }^{5}$ Speech-Aphasia: Motor, Sensory, global; Dysarthria; cannot be assessed; Nil.
The pathology encountered in plain Computed Tomography $(\mathrm{CT})$ brain was infarct in $76 \%(\mathrm{n}=14)$ and intracerebral hemorrhage $(\mathrm{ICH})$ in $18 \%(\mathrm{n}=27)$. However no subarachnoid hemorrhage was encountered in the study. $73.6 \%(\mathrm{n}=22)$ of $<45$ years and $76.7 \%(\mathrm{n}=92)$ of $\geq 45$ years had infarct. $16.7 \%(n=5)$ of $<45$ years and $18.3 \%(n=22)$ of $\geq 45$ years had ICH. $72 \%(n=108)$ of our patients had CVA during work of which $92.6 \%(\mathrm{n}=$ 100) had identifiable pathology in plain CT brain. Under this $85 \%(\mathrm{n}=85)$ had infarct and $15 \%(\mathrm{n}=15)$ had ICH. $28 \%(\mathrm{n}=42)$ developed stroke during sleep/as soon as waking up, of which of whom $71.4 \%(\mathrm{n}=30)$ had infarct and $28.6 \%(\mathrm{n}=12)$ had ICH. $73.9 \%(\mathrm{n}=85)$ of infarcts and $55.6 \%(\mathrm{n}=15)$ of ICH occurred during work. $26.1 \%$ $(n=30)$ of infarct and $44.4 \%(n=12)$ of ICH occurred during sleep/as soon as waking up.

Considering the site of involvement of stroke in the brain, subcortex accounted for 52.7\% $(\mathrm{n}=79) .43 .3 \%(\mathrm{n}$ $=13)$ of $<45$ years and $55 \%(n=66)$ of $\geq 45$ years had subcortical involvement. Other sites involved were subcortex + cortex in $18.7 \%(\mathrm{n}=28)$, only cortex in $15.3 \%$ $(n=23)$ etc.

Of the female young stroke patients, $21.4 \%(n=3)$ were in puerperal period and $28.6 \%(n=4)$ had a positive history of recurrent pregnancy loss. 60.9\% $(\mathrm{n}=70)$ of patients with infarct and $59.3 \%(n=16)$ of patients with ICH were tobacco abusers. $43.5 \%(n=50)$ of patients with infarct and $55.6 \%(n=15)$ of patients with ICH were alcohol abusers. $6 \%(n=9)$ of cases had history of recurrent CVA. $10 \%(\mathrm{n}=3)$ of $<45$ years and $5 \%$ $(n=6)$ of $\geq 45$ years had recurrent CVA.

\section{Discussion}

As with prior articles [5], in this study also the peak incidence of stroke is in $\geq 45$ years age group. Though majority of case $(80 \%)$ were seen in the elderly, stroke in the young carries special importance as they form the most productive age group. Young stroke has increased in the recent times with changing lifestyles and better diagnostic modalities. In accordance with prior Indian studies, our study population had $20 \%$ young strokes [6]. Considering the sex ratio, female predominance is seen in young stroke victims [7]. It is evident from this study as $22.2 \%$ of female young stroke patients in contrast to males $-18.4 \%$. Assessment of educational and occupational status revealed that $\geq 45$ years age group had more number of Illiterates and unemployed. Stroke is a quintessential medical emergency. CVA patients who receive neurological care within 6 hours of onset of symptoms have a 4 fold greater chance of good outcome than those treated after this acute period [8]. In this study the proportion of $<45$ years and $\geq 45$ years who were brought within 6 hours were found to be equal. 
In this study majority of them were right handed individuals, with only 3 left handed patients. So this data did not have significant impact on the study outcome.

Non contrast computed tomography brain is the first imaging modality adopted in CVA patients as it reliably distinguishes acute ICH from ischemia [9]. In this study also pathological process involved in the causation of stroke was evaluated using plain CT brain. In accordance to prior studies conducted in India, cerebral infarction was major pathology encountered (76\%) [10]. Recent Indian Stroke studies have shown ratio between infarction: ICH is 2.21:1 (Western countries-5:1) [11,12]. However in this study the ratio is $4.2: 1$. In both the age groups, infarction was the predominant pathology. Also infarction was the major pathology in both who had CVA during work and during sleep/as soon as waking up. $52.7 \%$ of the patients had only subcortical involvement which was the most common site seen in this study. $\geq 45$ years exceeded $<45$ years in subcortical involvement by $11.7 \%$.

Identification of risk factors for stroke [13] as well as an awareness of the relative importance of each and their interaction carries prime importance in the pathological outcome in both these age groups. Though innumerable risk factors exist for the occurrence of stroke, the most salient and common ones encountered in our setup and those risk factors whose modification has a great positive impact on the occurrence and outcome of stroke has been considered in this study [14]. DM, HT, Cardiac disorders, Smoking and long term Alcohol consumption are major risk factors in young adults as in elder population [15].
They are-Chronic Medical Illness such as-Hypertension [16], Diabetes Mellitus [17], Cardiac Disorders [18]; Adverse Personal Habits such as-Tobacco Abuse [19, 19], Alcohol Abuse [21]; Personality Types such asType A, Type B [22]. As far as the chronic medical illness is considered, the most common encountered is the HT seen in $60.7 \%$ of patients, followed by DM (33.3\%) and cardiac disorders (14.1\%) [20,23] (Figure 1).

Study of pattern of past medical illness in patients with infarct, showed that large number of patients were hypertensives $(29.8 \%)$ followed by the combination of HT $+\mathrm{DM}$ and $\mathrm{DM}+\mathrm{HT}+$ cardiac disorders $(6.1 \%)$ (Figure 2). Whereas in patients with $\mathrm{ICH}, 33.3 \%$ had $\mathrm{DM}+\mathrm{HT}$ followed by only HT (18.5\%) (Figure 3). Among the adverse habits, tobacco abuse was seen in the majority of patients $(60.7 \%)$. Most of the patients with infarct were tobacco abusers $(6.9 \%)$ and in those with ICH were alcohol abusers (55.6\%) (in accordance to prior studies) [24] (Table 2). Interestingly $70.1 \%$ of our study population had Type A personality, of whom males predominated.

In assessing the combination and their effects of risk factors, tobacco abuse and hypertension appear to act synergistically as stroke risk factors [25] which was evident in this study also by the following data-hypertensive tobacco abusers were $60.43 \%$ in contrast to only hypertensives without tobacco abuse were only $39.57 \%$. Similar relation of tobacco abuse with DM [26] and cardiac disorders was seen.

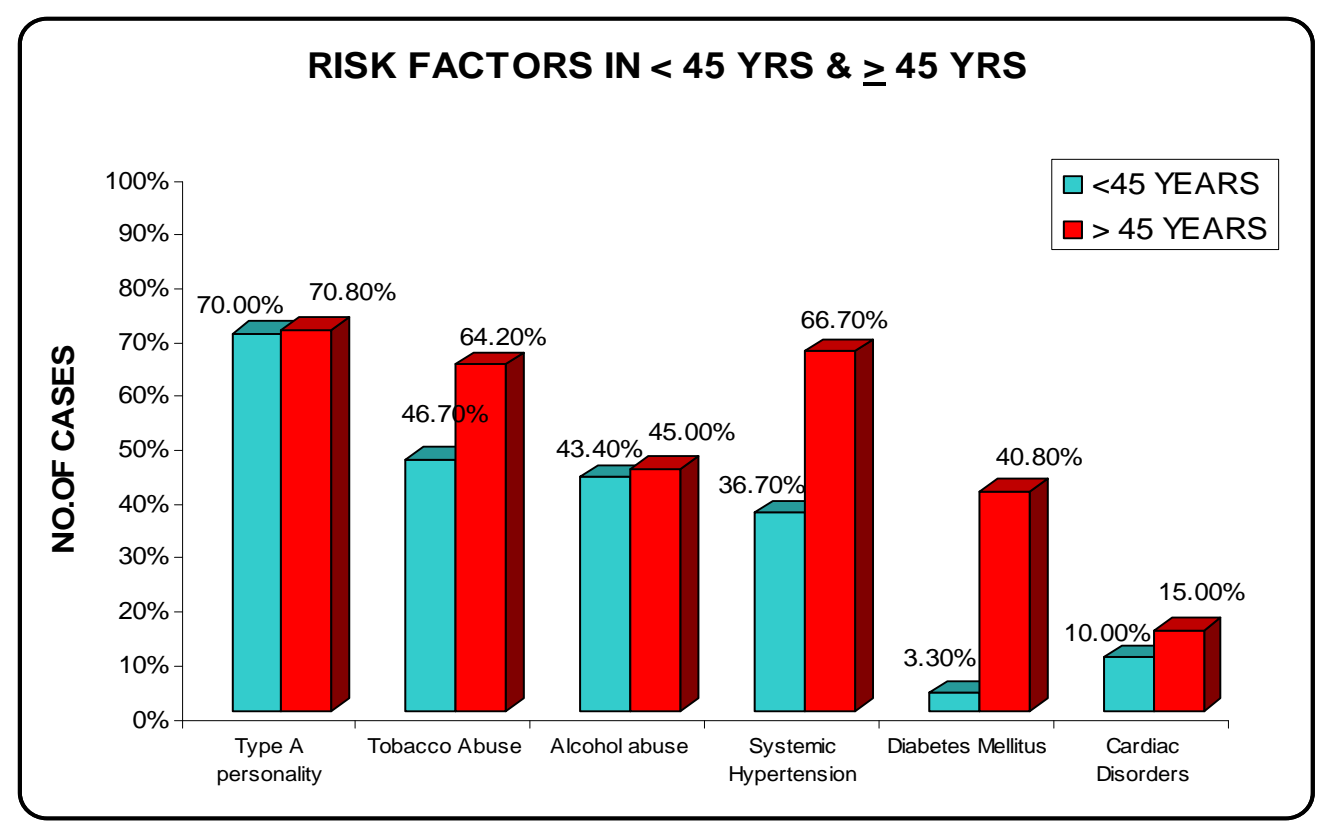

Note: The percentages given in the bar diagram indicate the percentages of patients who are $<45$ yrs and $\geq 45 \mathrm{yrs}$ with each of the following risk factors-Type A personality, Tobacco abuse, Alcohol abuse, Systemic Hypertension, Diabetes Mellitus and Cardiac disorders. This diagram compares the proportion of $<45 \mathrm{yrs}$ and $\geq 45 \mathrm{yrs}$ with these risk factors.

Figure 1. Risk Factors in $<45$ years and $\geq 45$ years. 


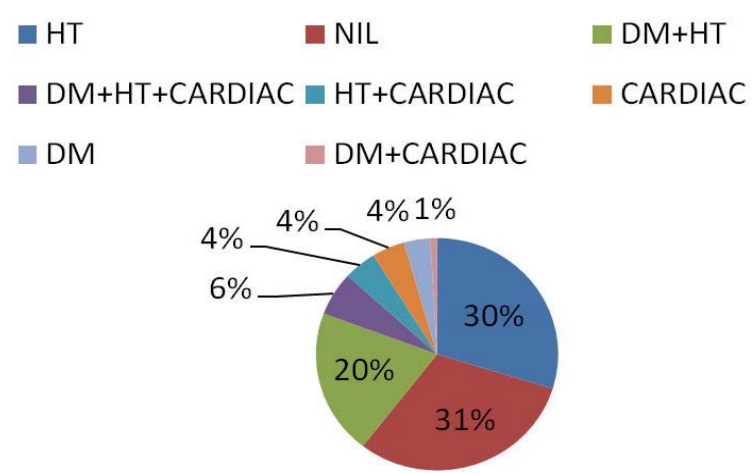

Note: This pie diagram gives the proportion of different comorbid medical illnesses seen in patients with cerebral infarction.

Figure 2. Cerebral infarction and comorbid medical illness.

Table 2. Adverse social habits and comorbid medical illness. ${ }^{1}$

\begin{tabular}{ccccc}
\hline & HT & DM & $\begin{array}{c}\text { CARDIAC } \\
\text { DISORDERS }\end{array}$ & NIL \\
\hline Tobacco & $\mathrm{n}=55$ & $\mathrm{n}=30$ & $\mathrm{n}=11$ & $\mathrm{n}=29$ \\
Abusers & $60.43 \%$ & $60 \%$ & $52.4 \%$ & $65.9 \%$ \\
& $60.43 \%$ & $33 \%$ & $12.1 \%$ & $31.9 \%$ \\
Non-Tobacco & $\mathrm{n}=39.57 \%$ & $\mathrm{n}=20$ & $\mathrm{n}=10$ & $\mathrm{n}=15$ \\
abusers & $39.57 \%$ & $33.9 \%$ & $16.9 \%$ & $25.4 \%$ \\
& $\mathrm{n}=36$ & $\mathrm{n}=21$ & $\mathrm{n}=11$ & $\mathrm{n}=25$ \\
$\begin{array}{c}\text { Alcohol } \\
\text { abusers }\end{array}$ & $39.6 \%$ & $42 \%$ & $52.4 \%$ & $56.8 \%$ \\
& $53.7 \%$ & $31.3 \%$ & $16.4 \%$ & $37.3 \%$ \\
Non Alcohol & $\mathrm{n}=55$ & $\mathrm{n}=29$ & $\mathrm{n}=10$ & $\mathrm{n}=19$ \\
abusers & $60.4 \%$ & $58 \%$ & $47.6 \%$ & $43.2 \%$ \\
& $66.3 \%$ & $34.9 \%$ & $12 \%$ & $22.9 \%$ \\
\hline
\end{tabular}

${ }^{1}$ Note: The percentage above the horizontal line indicates the proportion of patients with past medical illness having/not having adverse social habits. Similarly percentage below the horizontal line indicates the proportion of patients with/without adverse social habits with/without past medical illness.

According to quadrantic model of risk of stroke, there appears to be a "J" shaped relation between alcohol intake and risk. Moderate and heavy drinking reduces and increases the risk respectively [27]. The percentage of hypertensives who were alcohol abusers (39.6\%) was less than those who were not alcohol abusers (60.4\%). Similar pattern was observed in diabetics. However, in cardiac patients who were alcohol abusers were more than those who were not.

As an individual risk factor, tobacco abuse increased the risk of CVA as it was seen that tobacco abusers without past medical illness were $65.9 \%$. Similar pattern was also observed in alcohol abusers.

On exploring the risk factors, it was seen that the percentage of tobacco abusers among $\geq 45$ years was much greater than $<45$ years (by $17.5 \%$ ), whereas no significant difference was noted in the percentage of alcohol $\square \mathrm{NIL} \quad \mathrm{DM}+\mathrm{HT} \quad \mathrm{HT} \square \mathrm{DM}+\mathrm{HT}+\mathrm{CARDIAC}$

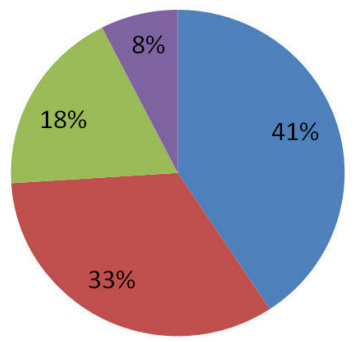

Note: This pie diagram gives the proportion of different comorbid medical illnesses seen in patients with ICH.

Figure 3. ICH and comorbid medical illness.

abusers in the two groups. The proportion of patients $\geq 45$ years with comorbid medical illness was found to be more than the patients $<45$ years.

On considering the medical risk factors in young stroke patient, prior studies have revealed important contribution by cardiac disorders [28]. In this study also, following systemic hypertension, cardiac disorders was the major factor involved in the causation of stroke. Recurrent CVA was most commonly seen in $<45$ years $(10 \%)$ [29].

To conclude, stroke in our country is very much on the rise and has accelerated the morbidity and mortality which has been evident by the data accumulated by prior studies. The occurrence of stroke steeply rises with age with its peak between 55 - 65 years. It was seen in this study also that patients $\geq 45$ years were $80 \%$ of the stroke patients. Though stroke in the young was seen to be less common $(20 \%)$ it is much more devastating, particularly with respect to productive years lost. Hence it is of paramount importance to consider it with much more greater vigour. This study showed a sex ratio with female predominance in young stroke victims with particular reference to the puerperal period. Though cerebral infarction outnumbered ICH, hemorrhage still was seen in $18 \%$ of patients. However the occurrence of $\mathrm{ICH}$ and cerebral infarction was equal in both age groups. Interestingly most of the patients with ICH were alcohol abusers in contrast to patient with infarcts, who were mainly tobacco abusers. This opens new avenues to explore the association between prediction of probable CVA pathology and adverse personal habits. As expected, systemic hypertension was the most common factor with significant contribution from Diabetes Mellitus. Risk factor analysis showed greater influence in $\geq 45$ years than young strokes. On exploration of factors in young stroke victims, next to systemic hypertension, cardiac disorders proved a significant contribution. There is a need for further research in young strokes, particularly population based studies to elucidate much more intricate factors 
involved in its causation.

Thus a holistic approach encompassing stroke awareness, further research studies and dispensing timely management of these victims in the need of the hour to contain the tough challenge of stroke in our country which is now poised to become a giant threat in near future.

\section{Acknowledgements}

We acknowledge the statistical assistance given by Mr. K. Boopathi, Biostatistician, National Institute of Epidemiology, Indian Council of Medical Research, Chennai.

\section{REFERENCES}

[1] S. Hartona, "Experiences from a Multicenter Stroke Register: A Preliminary Report," Bulletin of the World Health Organization, Vol. 54, No. 5, 1976, pp. 541-553.

[2] P. Bath, “Acute Stroke," In: D. Machin, S. Day and S. Green, Eds., Textbook of Clinical Trials, Wiley, Hoboken, 2006, p.179-180. doi:10.1002/9780470010167.ch13

[3] Asian Acute Stroke Advisory Panel, "Stroke Epidemiological Data of Nine Asian Countries," Journal of the Medical Association of Thailand, Vol. 83, 2000, pp. 1-7.

[4] S. K. Das, T. K. Banerjee, A. Biswas, D. K. Raut, C. S. Mukherjee, A. Chaudhari, et al., "A Prospective Community Based Study of Stroke in Kolkata, India," Stroke, Vol. 38, No. 3, 2007, pp. 906-910. doi:10.1161/01.STR.0000258111.00319.58

[5] P. M. Dalal, "Burden of Stroke-Indian Perspective," Journal of the Association of Physicians of India, Vol. 52, 2004, pp. 695-696.

[6] J. Abraham, P. S. S. Rao, S. G. Inbaraj, G. Shetty and C. J. Jose, "An Epidemiological Study of Hemiplegia Due to Stroke in South India," Stroke, Vol. 1, No. 6, 1970, pp. 477-481. doi:10.1161/01.STR.1.6.477

[7] H. Bevan, K. Sharma and W. Bradley, "Stroke in Young Adults," Stroke, Vol. 21, No. 3, 1990, p. 382. doi:10.1161/01.STR.21.3.382

[8] A. Davalos, J. Castillo, E. Martinez-Vila, et al., "Delay in Neurological Attention and Stroke Outcome," Stroke, Vol. 26, No. 12, 1995, p. 2233.

[9] R. Von Kummer, P. N. Nolte, H. Schnittger, et al., "Detectability of Cerebral Hemispheric Ischemic Infarcts by CT within 6 h of Stroke," Neuroradiology, Vol. 38, No. 1, 1996, pp. 31-33. doi:10.1007/s002340050188

[10] P. M. Dalal, "Burden of Stroke: Indian Perspective," International Journal of Stroke, Vol. 1, No. 3, 2006, pp. 164166. doi:10.1111/j.1747-4949.2006.00051.x

[11] T. K. Banerjee, C. S. Mukherjee and A. Sarkhel, "Stroke in the Urban Population of Calcutta: An Epidemiological Study," Neuroepidemiology, Vol. 20, No. 3, 2001, pp. 201207. doi: $10.1159 / 000054788$

[12] E. H. Lo, T. Dalkara and M. A. Moskowitz, "Mechanisms, Challenges and Opportunities in Stroke," Nature Reviews Neuroscience, Vol. 4, No. 5, 2003, pp. 399-412. doi:10.1038/nrn1106
[13] G. Boysen, J. Nyboe, M. Appleyord, et al., "Stroke Incidence and Risk Factors for Stroke in Copenhagen, Denmark," Stroke, Vol. 19, No. 11, 1988, p. 1345. doi:10.1161/01.STR.19.11.1345

[14] B. Herman, P. I. M. Schmintz, A. C. M. Leyten, et al., "Multivariate Logistic Analysis of Risk Factors for Stroke in Tilburg, Netherlands," American Journal of Epidemiology, Vol. 118, No. 4, 1983, pp. 514-525.

[15] R. X. You, J. J. McNei, H. M. O’Malley, S. M. Davis, A. G. Thrift and G. A. Donan, "Risk Factors for Stroke Due to Cerebral Infarction in Young Adults," Stroke, Vol. 28, No. 10, 1997, pp. 1913-1918. doi:10.1161/01.STR.28.10.1913

[16] JNC 7 Express, "The Seventh Part of the Joint National Committee on Prevention, Detection, Evaluation and Treatment of High Blood Pressure," US Department of Health and Human Services, National Institute of Health, Vol. 3, 2003, p. 5233.

[17] Expert Committee on Diagnosis and Classification of Diabetes Mellitus, "Follow-Up Report on the Diagnosis of Diabetes Mellitus," Diabetes Care, Vol. 26, 2003, pp. 3160-3167. http://care.diabetesjournals.org/content/27suppl-1/S5.full

[18] P. H. Davis, J. M. Dambrosia, B. S. Shoenberg, et al., "Risk Factors for Ischemic Stroke-A Prospective Study in Rochester, Minnesota," Annals of Neurology, Vol. 22, No. 3, 1987, pp. 319-327. doi:10.1002/ana.410220307

[19] R. D. Abott, B. L. Rodriguez, C. M. Burchfiel and J. D. Curb, "Physical Activity in Older Middle Aged Men and Reduced Risk of Stroke: The Honolulu Heart Program," American Journal of Epidemiology, Vol. 139, No. 9, 1994, pp. 881-893.

[20] P. A. Wolf and R. B. D. Agostino, "Epidemiology of Stroke,” In: H. J. M. Barnett, J. P. Mohr, B. M. Stein and F. M. Yatsu, Eds., Stroke Pathophysiology, Diagnosis and Management, 3rd Edition, Churchill Livingstone, Edinburgh, 1988, pp. 3-28.

[21] P. B. Gorlick, M. B. Rodin, P. Langenberg, et al., "Weekly Alcohol Consumption, Cigarette Smoking and the Risk of Ischemic Stroke: Results of Case Control Study at Three Urban Medical Centres in Chicago, Illinosis," Neurology, Vol. 39, No. 3, 1989, p. 339.

[22] R. B. Williams, "Hostility: Effect on Health and the Potential for Successful Behavioural Approaches to Prevention and Treatment," In: A. Baum, T. A. Revenson and J. E. Singer, Eds., Handbook of health psychology, Elbraum, Mahwah, 2001.

[23] C. M. Burchfiel, J. D. Curb, B. L. Rodriguez, et al., "Glucose Intolerance and 22 Year Stroke Incidence-The Honolulu Heart Program," Stroke, Vol. 25, No. 5, 1994, pp. 951-957. doi:10.1161/01.STR.25.5.951

[24] M. R. Goldman, E. L. Rogers and M. C. Rogers, "Subarachnoid Hemorrhage Associated with Unusual Electrocardiographic Changes," Journal of the American Medical Association, Vol. 234, No. 9, 1975, pp. 957-958. doi:10.1001/jama.1975.03260220061023

[25] M. R. Pandey, "Tobacco Smoking and Hypertension," The Journal of the Indian Medical Association, Vol. 97, 
No. 9, 1999, pp. 367-369.

[26] U. Keil, A. Liese, B. Filipiak, et al., "Alcohol, Blood Pressure and Hypertension," Novartis Foundation Symposium, Vol. 216, 1998, p. 125.

[27] R. L. Sacco, M. El Kind, B. Boden-Albala, et al., "The Protective Effect of Moderate Alcohol Consumption on Ischemic Stroke," Journal of the American Medical Association, Vol. 281, No. 1, 1999, pp. 53-60. doi:10.1001/jama.281.1.53

[28] A. Caroli, C. Marini, E. Ferranti, et al., "A Prospective Study of Cerebral Ischemia in the Young. Analysis of Pathogenic Determinants," Stroke, Vol. 24, No. 3, 1993, pp. 362-367. doi:10.1161/01.STR.24.3.362

[29] "Copenhagen Stroke Study: Stroke Recurrence, Predictors, Severity and Prognosis, Neurology," 1997. http/www.neurology.org/content/48/4/891.short 